\title{
Escape response of planktonic protists to fluid mechanical signals
}

\author{
Hans Henrik Jakobsen* \\ Danish Institute for Fisheries Research, Department of Marine and Coastal Ecology. Kavalergården 6, 2920 Charlottenlund, \\ Denmark \\ Marine Biological Laboratory, Strandpromenaden 5, 3000 Helsingør, Denmark
}

\begin{abstract}
The escape response to fluid mechanical signals was examined in 6 protists, 4 ciliates and 2 dinoflagellates. When exposed to a siphon flow, 3 species of ciliates, Balanion comatum, Strobilidium sp., and Mesodinium pulex, responded with escape jumps. The threshold deformation rates required to elicit an escape ranged between 1.8 and $3 \mathrm{~s}^{-1}$. Escape speeds varied between 100 to 150 body length $\mathrm{s}^{-1}$. Jump directions were non-random in all jumping species and had a negative geotactic component. In a grazing experiment with copepods, the predation mortality of a jumping ciliate was about 15 times lower than that of a non-jumping similar sized protist when the predator was Temora longicornis, which captures prey entrained in a feeding current. However, when the predator was the ambush-feeding copepod Acartia tonsa, the predation mortalities of jumping and non-jumping protists were of similar magnitude. Escape responses may thus be advantageous in some situations. However, jumping behaviour may also enhance susceptibility to some predators, explaining the different predator avoidance strategies (jumping or not) that have evolved in planktonic protists.
\end{abstract}

KEY WORDS: Escape behaviour - Ciliates · Dinoflagellates · Jumping $\cdot$ Strobilidium • Balanion • Mesodinium · Acartia tonsa $\cdot$ Temora longicornis

Resale or republication not permitted without written consent of the publisher

\section{INTRODUCTION}

Pelagic protists are exposed to a variety of metazoan predators, and they serve as a potential link between primary production and metazoans (reviewed in Stoecker \& Capuzzo 1990, Nielsen \& Kiørboe 1994, Wiackowski et al. 1994). Therefore, an appropriate avoidance reaction to approaching predators may be advantageous to protists by increasing their survival. Escape jumping seems to be a widespread response to predators among protists inhabiting freshwater and marine environments (e.g. Tamar 1965, 1979, Jonsson \& Tiselius 1990, Gilbert 1994, Jakobsen \& Hansen 1997). Metazoan grazing on a broad range of protist taxa, including jumping ciliates,

*E-mail: hhj@dfu.min.dk has been studied in the past. These studies have found differential grazing rates on similar-sized and similar-shaped protists (e.g. Jonsson \& Tiselius 1990, Burns \& Gilbert 1993, Gilbert \& Jack 1993, Gilbert 1994, Wiackowski et al. 1994, Wickham 1995). Some authors have suggested that jumping is the key factor determining predation mortality, although speciesspecific predator-prey interactions also may play a role (Wiackowski et al. 1994).

Jonsson \& Tiselius (1990) and Gilbert (1994) made detailed, direct, video observations on the predatorprey encounters between planktonic predators and jumping ciliates. They found that jumping ciliates responded to a remote signal, since they performed escape jumps prior to direct contact with a feeding rotifer or copepod. However the character and intensity of the signal that initiated the escape jump were not identified. 
The aim of the present study was to investigate the jumping behaviour of selected protists in a quantifiable flow field in order to identify the nature of the signal and the signal intensity that initiates a jump response. Also, the predation mortality of a jumping ciliate was tested against that of a non-jumping phytoflagellate to investigate the significance of protozoan jumping in avoiding predators with different feeding strategies.

\section{MATERIALS AND METHODS}

Organisms used. Four ciliates and 2 dinoflagellates were used in the experiments. The ciliates were the oligotrichs Strombidium sulcatum and Strobilidium sp., a prostomatid ciliate, Balanion comatum, and a haptorid ciliate, Mesodinium pulex. The dinoflagellates were the heterotrophic Gyrodinium dominans and the phototrophic Heterocapsa triquetra.

Strombidium sulcatum was supplied by T. Fenchel, University of Copenhagen. Cultures of Strobilidium sp., Balanion comatum, Mesodinium pulex and Gyrodinium dominans were established by enriching seawater samples with different phototrophs as prey, following the method of Buskey \& Hyatt (1995). All heterotrophs were cultured in $250 \mathrm{ml}$ transparent tissue bottles mounted on a plankton wheel ( 0.5 to $1 \mathrm{rpm}$ ), and fed appropriate phytoplankton cells (Table 1). Two of the ciliate species were cultured temporarily (Strobilidium sp. $<2 \mathrm{wk}$ and Mesodinium pulex $<3$ mo). Cell sizes were estimated from linear dimensions of cells fixed in Lugol solution, using an inverted microscope at a magnification of $1000 \times$, and were converted to volumes using appropriate volumetric formulas (Table 1).

Strobilidium sp. was identified from swimming behaviour (Lavrentyev 1995) and morphology of cells fixed in Lugol solution (Montagnes \& Lynn 1991). Balanion comatum was morphologically identical to the species redescribed by Jakobsen \& Montagnes (1999). Mesodinium pulex was identified from specimens fixed in Lugol solution and from live microscopical observations, according to Tamar (1992). Heterocapsa triquetra was kindly made available by the Scandinavian Culture Centre for Algae and Protozoa, Botanical Institute, University of Copenhagen. Gyrodinium dominans was identified from Hansen \& Larsen (1992). All protists were maintained in autoclaved seawater with added B1 nutrients (Hansen 1989) at a temperature of $15^{\circ} \mathrm{C}$. Phototrophic protists were maintained at an irradiance of 80 to $100 \mu \mathrm{mol}$ photons $\mathrm{m}^{-2} \mathrm{~s}^{-1}$, while heterotrophs were kept in dim light at an irradiance of 5 to $10 \mu \mathrm{mol}$ photons $\mathrm{m}^{-2} \mathrm{~s}^{-1}$. The culture of Temora longicornis was established by manually picking copepods from $200 \mu \mathrm{m}$ plankton-tow samples. Acartia tonsa originated from cultures at the Danish Institute of Fisheries Research. Both copepod species used in the grazing experiments were cultured following the methods of Støttrup et al. (1986) at $18 \pm 2{ }^{\circ} \mathrm{C}$.

Video setup. Jump responses of protists to a quantifiable flow disturbance generated by a suction siphon were studied. The set-up of the siphon-flow experiment was similar to that used by Fields \& Yen (1996) and Kiørboe et al. (1999). In a transparent aquarium $(25 \times 25 \times 50 \mathrm{~cm})$, an approx. $7 \mathrm{~cm}$ long siphon was mounted vertically in the bottom centre. The water left the aquarium through the siphon. The flow rate was adjusted by varying the distance between the outflow and the siphon tip and the water level in the aquarium. The water level in the container was never allowed to sink more than $5 \mathrm{~cm}$ during video recordings. Jump events were video-recorded with 2 horizontally mounted CCD (charge couple device) cameras viewing the siphon tip at perpendicular angles, thus ensuring that each camera represented either the $x, z$ or the $y, z$ plane. The video cameras were equipped with $105 \mathrm{~mm}$ macro camera lenses. The 2 pictures were combined in a video mixer that was connected to a VCR (50 fields $\mathrm{s}^{-1}$ ). Size calibration was done by filming a millimetre ruler both vertically and horizontally. Light was provided by 2 infrared light-emitting diodes placed in the focal point of $2(16 \mathrm{~cm} \varnothing)$ lenses, creating

Table 1. Protists used in suction-flow experiments, their size and prey organisms

\begin{tabular}{|lccl|}
\hline & $\begin{array}{c}\text { Size } \\
(\mathrm{ESD}, \mu \mathrm{m})\end{array}$ & $\begin{array}{c}\text { Spontaneous jumping } \\
\text { observed }\end{array}$ & Prey \\
\hline Ciliates & & No & Bacteria \\
Strombidium sulcatum & 25 & Yes & Hedomonas salina \\
Balanion comatum & 17 & Yes & Heterocapsa rotunda \\
Strobilidium sp. & 52 & Yes & Rhodomonas salina \\
Mesodinium pulex & 20 & No & \\
Dinoflagellates & 22 & No & \\
Gyrodinium dominans & 16 & & \\
Heterocapsa triquetra & &
\end{tabular}


parallel light beams through the experimental container into each camera (van Duren \& Videler 1995).

The flow field. The flow generated by a suction siphon is radially symmetric and irrotational (i.e., no vorticity). The flow can be characterised by its velocity $\left(v, \mathrm{~cm} \mathrm{~s}^{-1}\right)$, its deformation $\left(\Delta, \mathrm{s}^{-1}\right)$, and its acceleration $\left(a, \mathrm{~cm} \mathrm{~s}^{2}\right)$. These all vary with distance from the tip of the siphon $(r)$ and with the volume flow-rate $(Q)$ (for detailed descriptions of the properties of a siphon flow see Kiørboe et al. 1999):

$$
\begin{aligned}
& v(r)=\frac{Q}{4 \pi r^{2}} \\
& \Delta(r)=\frac{Q}{2 \pi r^{3}} \\
& a(r)=\frac{Q^{2}}{8 \pi^{2} r^{5}}
\end{aligned}
$$

Because protists follow the fluid flow, they cannot sense velocity per se but may potentially perceive fluid deformation and acceleration. Of these, fluid deformation is the most likely component to be perceived (see 'Discussion'). By substituting $r$ in Eq. (2) with the measured distance from the siphon at which the protists respond to the flow disturbance, the critical threshold deformation rate required to elicit a jump response can be estimated. Note that the exponents in Eqs. (1) to (3) are only valid for a system without boundary layers. Boundary layers may be created by the siphon and at the bottom of the experimental container. The actual exponent in each experiment was therefore determined from the regressions of particle velocities versus the distance to the siphon tip. I measured flow velocities through frame-by-frame mapping of neutrally buoyant detritus particles, which followed the flow towards the siphon. Particle positions were plotted on acetate transparencies covering the video monitor. The acetate transparencies were subsequently digitised into files containing $x, z$ and $y, z$ coordinates from each of the cameras.

Jump characteristic. In this study, jumps are defined as events with a $>5$-fold increase in swimming velocity within the time required to move on 1 body length and a jump path length longer than 10 body lengths. Spontaneous jumps were followed in undisturbed water (>35 jumps for each species). The time intervals between jumps were recorded and the jump frequencies calculated. Duration, start and end positions of jumps provoked by the fluid motion were mapped on acetate transparencies ( $\geq 50$ for each species). Only protists caught in the flow were considered. When cells jump in the flow field, their jump trajectory is affected by the drag of the ambient fluid motion. Hence, jump characteristics (velocity, distance and direction) are affected.
I corrected for this by subtracting the siphon flow field as described in Appendix 1. For Balanion comatum, an additional 39 spontaneous jumps performed in undistributed water were mapped on transparencies in order to compare characteristics of spontaneous with provoked jumps. Among the species that displayed jumping behaviour, only a fraction of individuals responded to suction flow. This fraction was estimated by following more than 50 cells of each jumping species in the siphon flow, and noting whether or not the cells were responding.

Grazing experiment. The efficiency of escape jumps as a predatory defence mechanism was examined by offering the copepods Temora longicornis or Acartia tonsa a mixed diet of the jumping ciliate Balanion comatum and the non-jumping phototrophic dinoflagellate Heterocapsa triquetra. The 2 prey species are of almost similar size, but differ in escape behaviour. $B$. comatum jumps, while $H$. triquetra is unable to do so. Because the ciliate was raised on a diet of Rhodomonas salina (ESD $7.5 \mu \mathrm{m}$ ), these cells were also available in equal concentrations in both the grazing experiments.

The 2 copepod species have distinct feeding strategies. Temora longicornis generates a feeding current while Acartia tonsa is an ambush-predator when feeding on motile prey (Kiørboe et al. 1996). Grazing mortalities of Heterocapsa triquetra and Balanion comatum were examined at a total cell concentration of approx. 0.3 to $0.4 \mathrm{ppm}$, using equal amounts of each prey and similar amounts of the ciliate prey Rhodomonas salina added to all treatments. Grazing experiments were run with 4 replicates, along with triplicate controls without copepods. Grazing experiments were performed in seawater with B1 nutrients added (Hansen 1989) at a constant irradiance of 5 to $8 \mu \mathrm{mol}$ photons $\mathrm{m}^{-2} \mathrm{~s}^{-1}$. Experiments were carried out in $700 \mathrm{ml}$ flasks mounted on a slow rotating $(0.5 \mathrm{rpm})$ plankton wheel (diameter $=0.5 \mathrm{~m}$ ) at $18 \pm 2{ }^{\circ} \mathrm{C}$. Each flask was sealed with plastic film between the stopper and the flask to avoid air bubbles. Between 20 and 30 female copepods were added to each grazing flask. Prey cells were growing exponentially prior to use. Grazing rates were calculated according to Frost (1972).

\section{RESULTS}

Observations of undisturbed cells showed that only 3 of the studied species performed spontaneous jumps, namely Balanion comatum, Strobilidium sp. and Mesodinium pulex (Table 1). Since the purpose of the present study was to study escape characteristics of protists, the study concentrated on these 3 jumping species. 

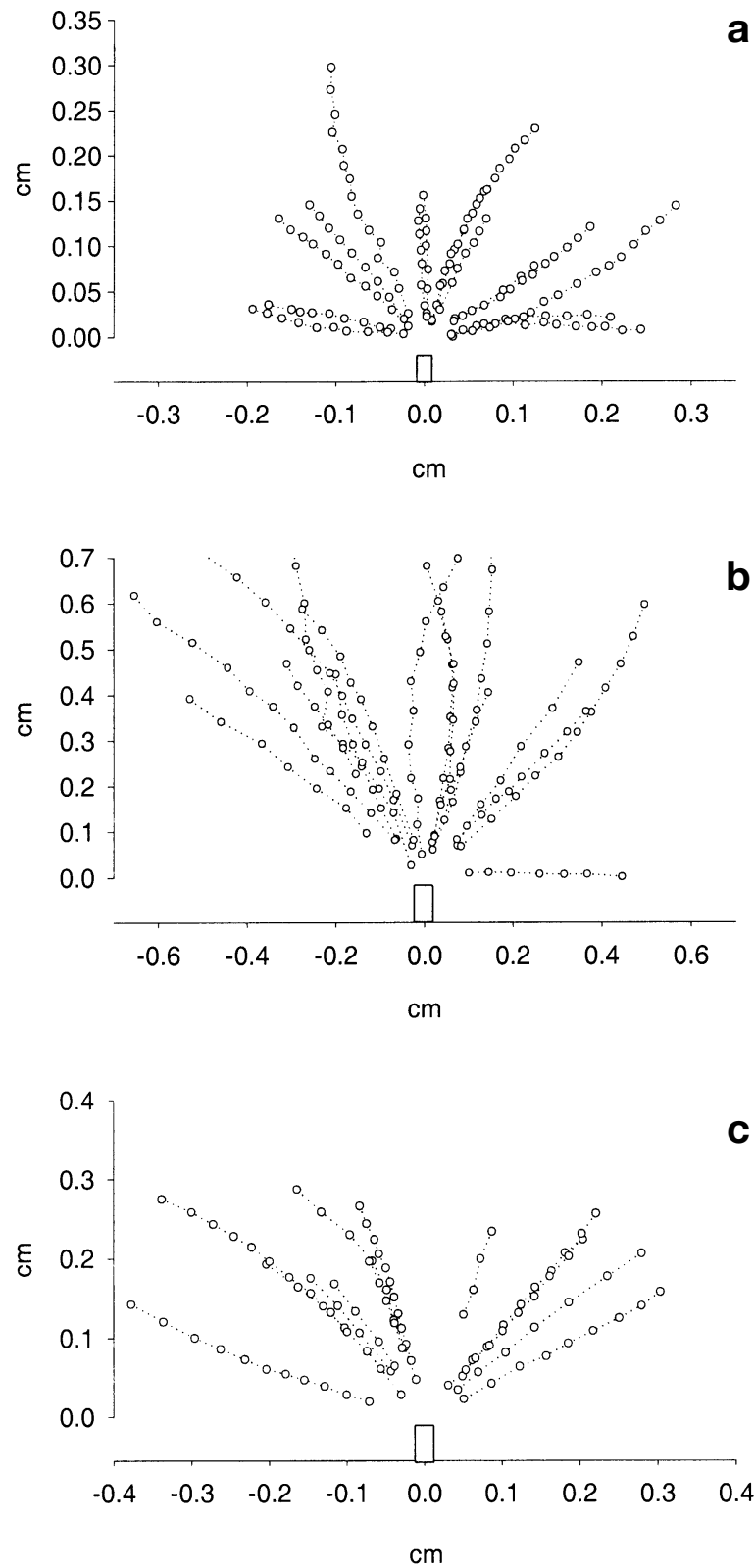

Fig. 1. Flow lines toward siphon tip in experiments run with (a) Balanion comatum, (b) Strobilidium sp. and (c) Mesodinium pulex. Both axes: distance from siphon

\section{Flow field}

Because cell sizes of the examined ciliates differed by a factor of 3, different magnifications and, hence, different flow rates were used to ensure that all escape responses occurred within the field of view. The lower the magnification, the larger the siphons and thus the higher the flow rate (Table 2). The flow lines, folded onto the plane, are shown in Fig. 1. Away from the siphon tip the flow lines are not straight. However,
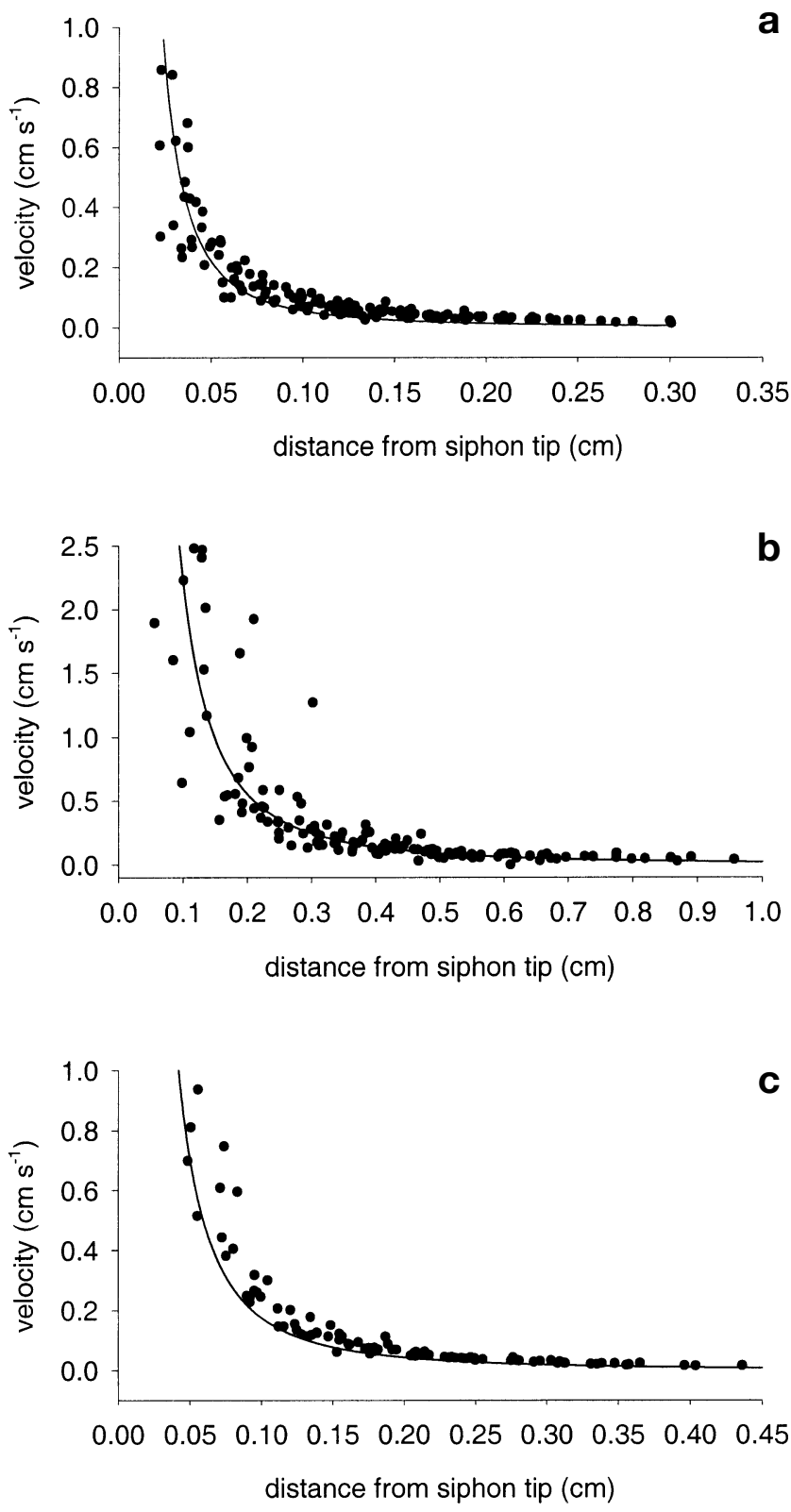

Fig. 2. Flow velocity as a function of distance from siphon tip in experiments run with (a) Balanion comatum, (b) Strobilidium sp. and (c) Mesodinium pulex. Lines are the ideal lines computed with Eq. (2) with a slope of -2

Table 2. Siphon tip diameter and flow $(Q)$ characteristics in experiments with jumping ciliates. The slope is the exponent to be inserted into Eq. (2). Numbers in parentheses: $R^{2}$ values

\begin{tabular}{|lccc|}
\hline Species & $\begin{array}{c}\text { Siphon tip } \\
\text { diameter }(\mathrm{cm})\end{array}$ & $\begin{array}{c}\text { Q } \\
\left(\mathrm{ml} \mathrm{s}^{-1}\right)\end{array}$ & Slope \\
\hline Balanion comatum & $2.5 \times 10^{-2}$ & $0.69 \times 10^{-2}$ & $-1.58(0.92)$ \\
Strobilidium sp. & $4.8 \times 10^{-2}$ & $27.90 \times 10^{-2}$ & $-1.93(0.80)$ \\
Mesodinium pulex & $2.8 \times 10^{-2}$ & $2.21 \times 10^{-2}$ & $-1.94(0.94)$ \\
& & & \\
\hline
\end{tabular}


within the region where jumps were provoked by fluid motion, the lines are straight, indicating that the flow field is symmetrical around the siphon tip. Flow velocity varied with radial distance from the siphon tip almost as expected. The slopes of the logarithmic regressions between flow velocity and distance from the siphon tip were close to -2 in the experiments involving Mesodinium pulex and Strobilidium sp., but scaled with a somehow higher exponent in the experiment with Balanion comatum (Fig. 2).

\section{Jump characteristics and deformation rate}

Frequencies of spontaneous jumps were low in all 3 jumping species (Table 3). Balanion comatum and Strobilidium sp. jumped less than once per minute ( 0.58 and $0.46 \mathrm{~min}^{-1}$, respectively). The spontaneous jump frequency of Mesodinium pulex was not quantified, but was very much lower. The spatial distribution of jump positions of $B$. comatum relative to the siphon tip was random when siphon flow was not applied (Fig. 3). Those species that did not jump spontaneously (Table 1) could not be provoked to jump in the siphon flow.
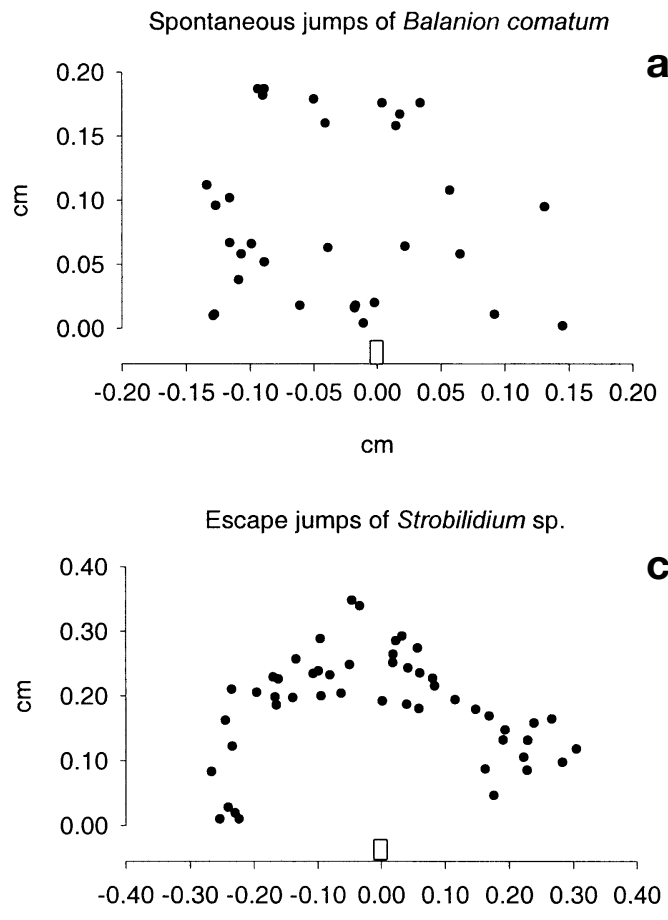

$\mathrm{cm}$
Table 3. Observations of spontaneous jumping by cells in the experimental container before applying suction flow. No quantitative observations were made on Mesodinium pulex since its spontaneous jump frequency was extremely low. n: number of cells observed of each species. SD: standard deviation. nd: no data

\begin{tabular}{lcccc} 
Species & $\mathrm{n}$ & $\begin{array}{c}\text { Mean observation } \\
\text { time }\left(\mathrm{s} \mathrm{cell}^{-1}\right)\end{array}$ & $\begin{array}{c}\text { Jump frequency } \\
\left(\mathrm{min}^{-1}\right)\end{array}$ & $\mathrm{SD}$ \\
\hline Balanion comatum & 54 & 63.46 & 0.58 & 1.44 \\
Strobilidium sp. & 35 & 45.93 & 0.46 & 1.2 \\
Mesodinium pulex & nd & nd & nd & nd \\
\hline
\end{tabular}

When flow was applied, ciliates were caught by the flow and drawn towards the siphon tip. At a certain distance from the siphon tip, the hydromechanical signal elicited an escape jump in some of the ciliates. The spatial distribution of provoked jumps forms a dome around the siphon tip for all 3 jumping species and indicates that the cells respond to a well-defined threshold signal created by the siphon flow (Fig. 3). The threshold deformation rates $\left(\Delta, \mathrm{s}^{-1}\right)$, calculated from Eq. (2), ranged between 1.8 and $3.0 \mathrm{~s}^{-1}$ in the studied ciliates. The threshold deformation rates of the 2 largest ciliates were not significantly different from each other but were significantly higher than that of Balanion comatum (Kruskal-Wallis test using
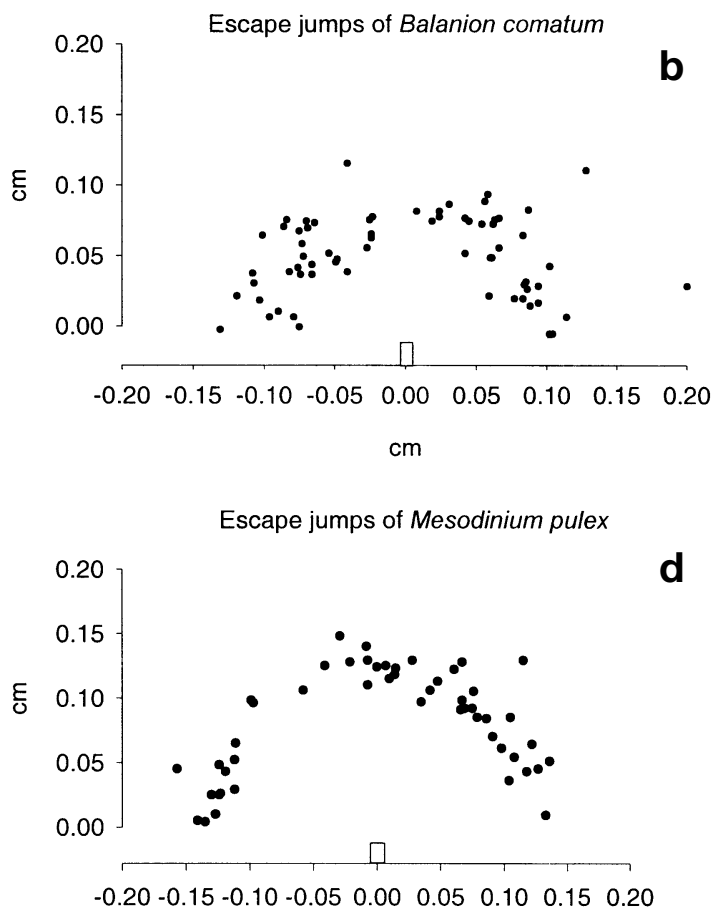

$\mathrm{cm}$

Fig. 3. Initial positions of jumps. (a) Spontaneous jumps by Balanion comatum before suction flow was applied. (b, c, d) Escape jumps in Balanion comatum, Strobilidium sp. and Mesodinium pulex, respectively. Both axes: distance from siphon 
Dunn's test for multiple comparisons; $\mathrm{p}<0.05)$. Only a fraction of the entire population of jumping ciliates responded to the siphon flow with escape jumps (Table 4).

Jump distance (Table 5, Fig. 4) is defined as the distance between the start position and the flowcorrected end position of the jump trajectory. Average specific jump distances were 44, 15 and 99 body lengths for Balanion comatum, Strobilidium sp. and Mesodinium pulex, respectively. Relative escape velocities were 140 body lengths $\mathrm{s}^{-1}$ in B. comatum, while both Strobilidium sp. and M. pulex jumped at about 100 body lengths $\mathrm{s}^{-1}$. There were no differences in jump speed and duration between spontaneous and provoked jumps in B. comatum (Kruskal-Wallis test; jump lengths: $\alpha=0.05, p=0.33$; jump duration: $\alpha=$ $0.05, \mathrm{p}=0.7407)$.

\section{Escape directions}

Escape direction can be viewed either as the angle to the vertical $\left(\theta_{\beta}\right)$ or as the angle relative to the flow direction ( $\theta_{\alpha i}$ Table 6$)$. Jump distances and directions relative to gravity have been plotted in Fig. 4. Jump directions, whether examined relative to gravity or to flow direction, were non-random in all cases $\left(\chi^{2}\right.$-test; Table 6). All ciliates jumped mainly horizontally to slightly upwards. There was a small, but insignificant difference in the direction of spontaneous and provoked jumps in Balanion comatum. However, jump direction relative to gravity varied significantly with the position of jump initiation in 2 of the studied spe-
Table 4. Observations on cells caught in suction flow. \% observed jumping: percentage of cells caught in the siphon flow that jumped. n: number of observed cells

\begin{tabular}{|lcc|}
\hline Species & $\mathrm{n}$ & \% observed jumping \\
\hline Balanion comatum & 75 & 71 \\
Strobilidium sp. & 75 & 51 \\
Mesodinium pulex & 51 & 39 \\
\hline
\end{tabular}

cies. The jump direction relative to gravity $\left(\theta_{\beta}\right)$ varied with the suction flow direction $\left(\theta_{\mathrm{x}}\right)$, implying that the jump direction is somewhat influenced by the flow direction (Table 7).

\section{Grazing mortality}

Clearance rates of Temora longicornis with the jumping Balanion comatum and the non-jumping Heterocapsa triquetra showed a pronounced significant difference (Student's $t$-test, $t=5.366, \mathrm{p}=0.002$ ). Clearance with the non-jumping $H$. triquetra was about $43 \mathrm{ml}$ female $\mathrm{e}^{-1} \mathrm{~d}^{-1}$, which is approx. 15 times higher than the $3 \mathrm{ml}$ female $\mathrm{e}^{-1} \mathrm{~d}^{-1}$ measured with the jumping ciliate B. comatum (Fig. 5). On the other hand, the ambush-feeding copepod Acartia tonsa cleared the 2 at identical rates ( $t$-test, $t=0.359, \mathrm{p}=0.732$ ) on 6 to $7 \mathrm{ml}$ female $^{-1} \mathrm{~d}^{-1}$ (Fig. 5). Thus, the escape response of $B$. comatum appears to be an efficient predator defence towards a copepod with a feeding current but inefficient towards an ambush-feeding copepod.

Table 5. Data $(\operatorname{avg} \pm \mathrm{SD})$ on deformation threshold and jump distance, duration and velocity of jumping ciliates

\begin{tabular}{|lccccc|}
\hline Species & $\mathrm{n}$ & $\begin{array}{c}\text { Threshold } \\
\text { deformation } \\
\text { rate }\left(\Delta \mathrm{s}^{-1}\right)\end{array}$ & $\begin{array}{c}\text { Escape } \\
\text { distance } \\
(\mathrm{cm})\end{array}$ & $\begin{array}{c}\text { Duration } \\
(\mathrm{s})\end{array}$ & $\begin{array}{c}\text { Jump } \\
\text { velocity } \\
\left(\mathrm{cm} \mathrm{s}^{-1}\right)\end{array}$ \\
\hline Balanion comatum (spontaneous jumps) & 39 & - & $0.064 \pm 0.023$ & $0.28 \pm 0.11$ & $0.23 \pm 0.03$ \\
Balanion comatum (provoked jumps) & 69 & $1.8 \pm 0.8$ & $0.070 \pm 0.028$ & $0.30 \pm 0.15$ & $0.25 \pm 0.071$ \\
Strobilidium sp. & 51 & $3.0 \pm 1.5$ & $0.076 \pm 0.034$ & $0.15 \pm 0.16$ & $0.52 \pm 0.13$ \\
Mesodinium pulex & 50 & $2.4 \pm 0.7$ & $0.197 \pm 1.30$ & $1.30 \pm 0.69$ & $0.21 \pm 0.06$ \\
\hline
\end{tabular}

Table 6. Mean angular direction of ciliate jumps (avg $\pm \mathrm{SD}) \cdot \chi^{2}$-tests were used to determine whether jump directions were random; $\mathrm{p}$ values indicate possibilities of jump directions being random. Sample sizes as in Table 5

\begin{tabular}{|c|c|c|c|c|}
\hline \multirow[t]{2}{*}{ Species } & \multicolumn{2}{|c|}{ Relative to gravity } & \multicolumn{2}{|c|}{ Relative to flow line } \\
\hline & $\theta_{\beta}$ & $\mathrm{p}$ & $\theta_{\alpha}$ & $\mathrm{p}$ \\
\hline Balanion comatum (spontaneous jumps). & $78 \pm 59$ & $<0.05$ & & \\
\hline Balanion comatum (provoked jumps) & $92 \pm 33$ & $<0.001$ & $97 \pm 33$ & $<0.001$ \\
\hline Strobilidium sp. & $98 \pm 42$ & $<0.001$ & $82 \pm 27$ & $<0.001$ \\
\hline Mesodinium pulex & $118 \pm 22$ & $<0.001$ & $53 \pm 17$ & $<0.001$ \\
\hline
\end{tabular}




\section{Spontanous jump of Balanion comatum}

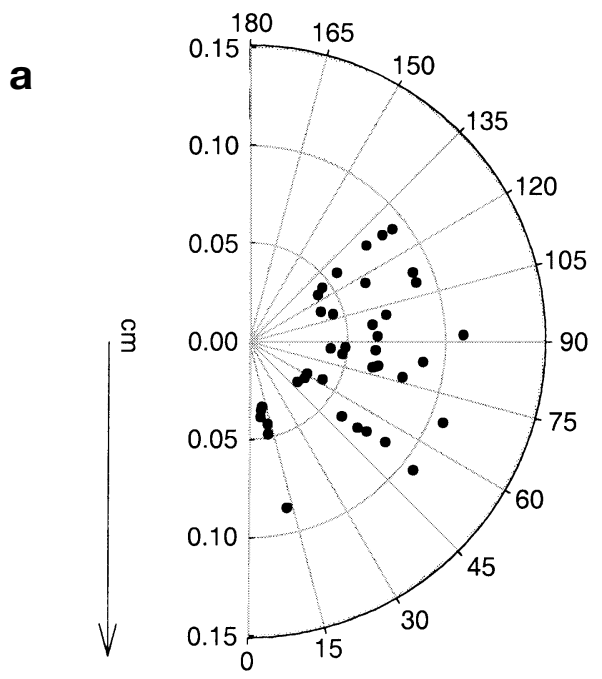

Escape jumps of Strobilidium sp.

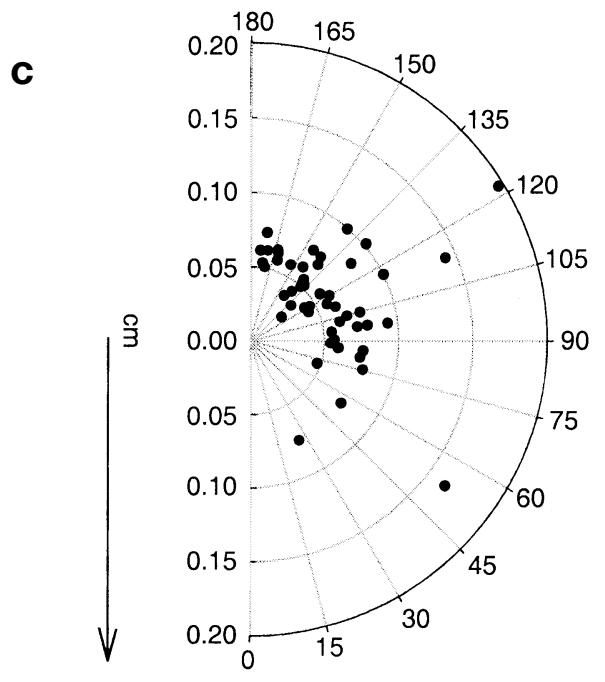

\section{Escape jumps of Balanion comatum}

b

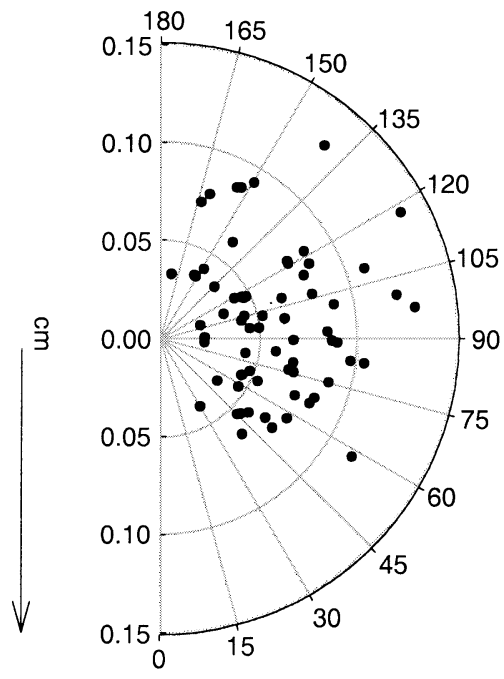

Escape jumps of Mesodinium pulex

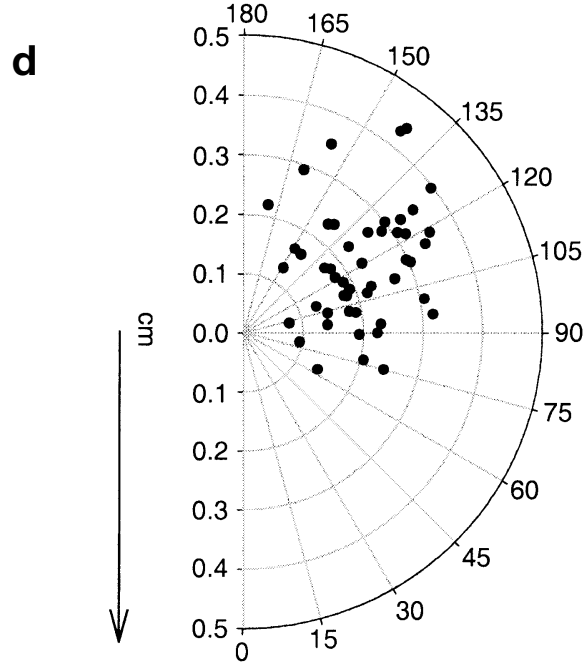

Fig. 4. Jump distance and jump angle relative to gravity in polar coordinates. (a) Spontaneous jumps by Balanion comatum. (b, c, d) Escape jumps by Balanion comatum, Strobilidium sp. and Mesodinium pulex, respectively. $0^{\circ}$ : direction of gravity

\section{DISCUSSION}

When a predator is perceived by a jumping ciliate, an efficient jump response should be immediate in order to avoid the approaching predator. The cue is therefore unlikely to be of a chemical nature, since dissolved chemicals propagate only slowly by diffusion (Berg 1983), and much slower than the swimming speed of most aquatic metazoans. Moreover, many planktonic protist predators create a feeding current, and it is not
Table 7. Correlation between jump angle relative to gravity and flow line. Sample sizes as in Table 5. Test values are equal to $t=r\left(\frac{n-2}{1-r^{2}}\right)$ and are a $t$-distribution (Sokal \& Rohlf 1998)

\begin{tabular}{|lccc|}
\hline Species & $\mathrm{r}^{2}$ & $t$ & $\mathrm{p}$ \\
\hline Balanion comatum & 0.10 & 2.73 & $<0.01$ \\
Strobilidium sp. & 0.26 & 4.17 & $<0.01$ \\
Mesodinium pulex & 0.07 & 1.92 & $>0.05$ \\
\hline
\end{tabular}



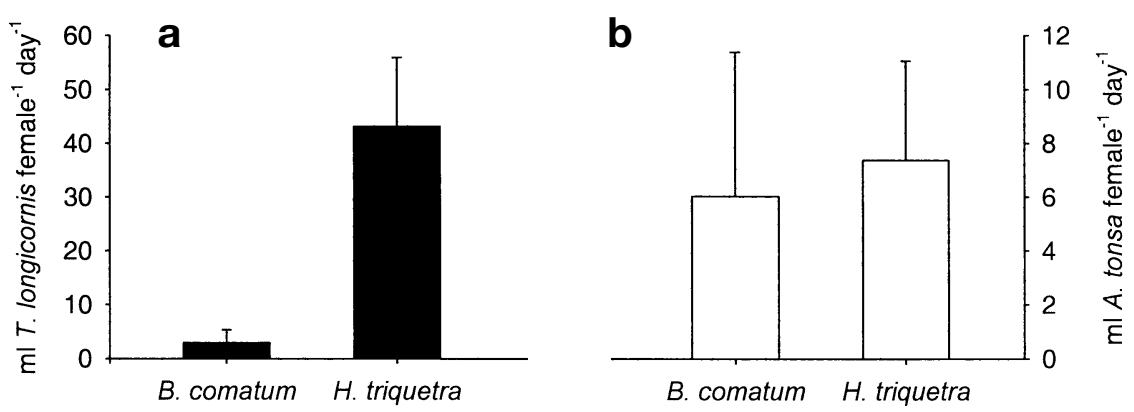

Fig. 5. Clearance rates $\left(\mathrm{ml}\right.$ female $\left.\mathrm{e}^{-1} \mathrm{~d}^{-1}\right)$ of the copepods Temora longicornis and Acartia tonsa on mixed prey assemblages. (a) T. longicornis feeding on Balanion comatum and Heterocapsa triquetra. (B) A. tonsa feeding on B. comatum and H. triquetra

likely that chemicals liberated from these predators diffuse upstream in their feeding currents. Previous observations of ciliates responding to predators suggest that escape jumps are initiated at some distance from the predators (Jonsson \& Tiselius 1990, Gilbert 1994), and the signal is therefore most likely to be of a hydromechanical nature. However, the intensity and nature of the signal remain unexplained. The well-defined distance from the siphon at which the escape jumps are elicited (Fig. 3) in the present experiments suggests that the jump is initiated by a hydromechanical signal of a well-defined threshold strength.

An approaching predator generates a hydromechanical signal, which can be perceived by the potential prey as vorticity, fluid deformation, or acceleration (Kiørboe \& Visser 1999). The siphon fluid flow is irrotational, thus excluding vorticity in the present experimental set-up. Acceleration is perceived as an increase in the gravity field, and at least 2 models of gravity perception have been suggested for ciliates (reviewed by Machemer \& Bräucker 1992). It has been demonstrated experimentally that ciliates do perceive acceleration and that the threshold at which ciliates and flagellates respond ranges between 0.16 and $0.3 \times g$ (Häder et al. 1996, Hemmersbach et al. 1996). The magnitude of fluid acceleration at the point where jumps were initiated in the present siphon flow experiments $\left(10^{-5}\right.$ to $10^{-6} \times g$, computed from Eq. 3) is several orders of magnitude lower than the threshold for detection of gravity. From a range of copepod feeding-current velocities (reviewed in Kiørboe et al. 1999), the maximum acceleration rates of feeding currents were estimated using appropriate formulas (Kiørboe \& Visser 1999). The highest fluid acceleration rate was approx. $0.02 \times g$ (approx. one-eighth of the gravity threshold detection level of Paramecium biaurelia) in the feeding current of the copepod Pleuromamma xiphias (Fields \& Yen 1996). Thus, acceleration is unlikely to provide a perceivable signal to protists, neither in my experiments nor in the flow field generated by metazoan predators. Jumps are more likely to be elicited by the activation of mechanoreceptor channels located in the ciliate membrane by ambient fluid deformation. The mechanoreceptors of ciliates have been shown to respond to deformation by depolarising their cell membrane, either upon direct mechanical contact or as a response to hydraulic pressure waves created by a micropipette positioned a certain distance away from the cell (Naitoh \& Eckert 1969).

The ciliates that were caught in the suction flow travelled for a while along with the flow lines towards the siphon before they responded by jumping. It is intuitively clear that the earlier the ciliate responds to the flow, the higher its chance of avoiding the pipette or of avoiding contact with a potential predator. However, the ciliates studied here did not respond until the ambient water disturbance reached a threshold deformation rate of 2 to $3 \mathrm{~s}^{-1}$ (Table 5). The deformation rates that elicit jumps in ciliates are of the same upper magnitude as the highest fluid deformation rates arising from turbulence in the upper ocean (data reviewed in Kiørboe \& Saiz 1995). The peak deformation rates in feeding currents of copepods range between 5 and $17 \mathrm{~s}^{-1}$ (data reviewed by Kiørboe et al. 1999). Thus, the sensitivity threshold of ciliates lies within a narrow window defined as a trade-off between successful predator avoidance and inordinate jumping in response to non-predator water disturbances induced by turbulence.

The threshold deformation rates in ciliates are of the same order of magnitude as the threshold deformation rates in metazoans (reviewed by Kiørboe et al. 1999). However, some fundamental differences prevail. Copepods detect fluid deformation as a fluid velocity difference between their sensory setae and the ambient water (Strickler \& Bal 1973, Yen \& Fields 1992, Kiørboe et al. 1999), while ciliates probably detect fluid deformation as deformation of the cell membrane (Naitoh \& Eckert 1969). In the case of copepods, signal strength is determined by the distance between the setae and the centre of the copepod, scaling the signal 
strength with animal size (Kiørboe et al. 1999). The sensory system in ciliates is probably independent of organism size because their sensory system depends on the number of mechanoreceptors per unit surface area of the cell membrane rather than the size of the cell.

The 3-dimensional shape of the flow fields of a filtering copepod can be described as a funnel-shaped structure with the flow accelerating towards the tip of the funnel where the mouth is located (Strickler 1985, Tiselius \& Jonsson 1990, Yen \& Fields 1992). A jumping ciliate caught in a suction flow of a filtering predator may adapt its jump angle in a way that optimises the chances of a successful jump, i.e. bringing the cell out of reach of the predator. If the ciliate jumps towards the predator (jump angle relative to the flow line $=0^{\circ}$ ), the risk of being eaten is increased. If the jump is in the opposite direction, away from the predator (jump angle relative to the flow line $=180^{\circ}$ ), the organism still remains within the predator flow field and the organism must consequently perform several jumps in order to avoid being sucked back into contact with the predator. The mean jump angles relative to the flow line found in the jumping species in this study are almost perpendicular to the flow line (range $=53$ to $97^{\circ}$ ). Jump directions perpendicular to the flow direction guide the ciliates in the direction that most efficiently brings them out of the flow field created by a copepod. The underlying mechanism responsible for the jump angle relative to the flow line may either be differential activation of the mechanoreceptors embedded in the cell membrane, or may be a result of the passive orientation of the ciliate cell in the flow field, as described by Visser \& Jonsson (2000). However, this needs to be investigated further.

Gilbert (1994) compared the swimming speed of spontaneous and provoked jumps in the ciliate Strobilidium velox and found no significant difference. A similar pattern with identical jump velocities and jump lengths of provoked and spontaneous jumps in Balanion comatum suggests that the underlying mechanisms of jumping are of the same nature, whether or not the ciliates are hydromechanically provoked. It also indicates that ciliates are unable to graduate their response relative to a predator in regard to jump speed and duration.

\section{Jumping as a predator-escape defence mechanism}

I have here viewed jump behaviour elicited by hydromechanical disturbances as a defence mechanism towards predation. In fact, the feeding experiments with the copepods Temora longicornis and Acartia tonsa did show that the jumping ciliate bene- fited from a substantially lower predator mortality than the non-jumping dinoflagellates when the predator was preying with a feeding current. On the other hand, the raptorial $A$. tonsa does not swim, but sinks slowly through the water when preying on motile prey. The fluid signal generated by the slow-sinking $A$. tonsa is less than the threshold required to elicit an escape response in ciliates (see Kiørboe \& Visser 1999 ). Thus, protist escape jumps are only efficient against certain predator strategies.

However, the ciliate Strombidium sulcatum and the dinoflagellates examined in this study did not jump at all. Why then, have not all protists developed jumping capabilities? One may speculate that jumping, which also occurs spontaneously, involves some risk of predation. Copepods detect their prey from the hydromechanical signal produced by the swimming of prey organisms (Kerfoot 1978), and it has been argued that copepods perceive prey cells by the fluid velocity generated by the moving prey (Kiørboe \& Visser 1999). Kiørboe \& Visser (1999) estimated that the threshold fluid velocity necessary to elicit an attack response in the ambush-feeding copepod Oithona similis is $0.004 \mathrm{~cm} \mathrm{~s}^{-1}$ and that the 'reaction distance' of a copepod to its prey depends on prey size and prey velocity. The reaction distance, defined as the distance from the prey to a given point in the ambient water where it can be perceived by the predator, can be estimated using the 'di-pole' model given in Svensen \& Kiørboe (2000). Application of this model to the data on jumping ciliates given in the present study and the data of Strobilidium velox studied by Gilbert (1994) suggests that the reaction distance at which a copepod like $O$. similis reacts to a jumping ciliate increases with factors of between 2.5 to 7 over the reaction distance to a non-jumping protist. This increase is substantial, particularly because the encounter ('clearance') rate roughly increases with the square of the reaction distance. Non-jumping species may have an advantage in their lesser detectability by predators. Thus, the optimal predator avoidance behaviour of a protist is a trade-off between escaping and hiding from planktonic predators.

Acknowledgements. This work was supported by a grant from the Danish Research Academy and by a grant from the Danish Natural Science Research Council to Professor Thomas Kiørboe (no. 9801391). Thomas Kiørboe provided insightful help and discussions in planing, performing and understanding the present experiment and criticised earlier drafts of the manuscript. Dr Andy Visser made the fluid correction model in the Appendix and provided crucial help in understanding the physical concepts of the fluid dynamics. Dr Per Juel Hansen carefully reviewed and criticised an earlier draft of the manuscript. Lars W. Pedersen programmed the software used to digitise the transparencies into ASCII files and helped set up the video gear for filming in 3D. 
Appendix 1. Correction for drag of fluid on jump direction

Correction to the escape jump for ambient fluid motion is facilitated by a 3 -fold transformation of the coordinates. The jump path, described by the coordinates $x_{\text {start }}, y_{\text {start }}, z_{\text {starti }}$ $x_{\text {end }} y_{\text {end }}, z_{\text {end }}$, is transformed to the coordinates ( $x_{\text {start }}^{\text {III }} y_{\text {start }}^{\text {III }}$ $\left.x_{\text {end, }}^{I I I} Y_{\text {end }}^{I I I}\right)$ lying in the plan of the jump trajectory. The end point ( $\left.x_{\text {end }}^{I I I}, y_{\text {end }}^{I I I}\right)$ is subsequently corrected for ambient water motions into a new end point $\left(x_{\text {end }}^{* I I I}, y_{\text {end }}^{* I I I}\right)$ as described below. After correcting for ambient water motion, the jump angle relative to the flow $\left(\theta_{\alpha}^{*}\right)$ is determined. Finally the jump vector $\left(x_{\text {start }}^{I I I} y_{\text {start }}^{I I I I} x_{\text {end }}^{* I I I}, y_{\text {end }}^{* I I I}\right)$ is rotated back to the original 3 -dimensional system $\left(x_{\text {start }}, y_{\text {start }}, z_{\text {starti }} x_{\text {end, }}^{*} y_{\text {end }}^{*}\right.$ $Z_{\text {end }}^{*}$ ). From these back-rotated coordinates, the jump angle relative to gravity $\left(\theta_{\beta}\right)$, jump length and jump speed could be calculated. Please refer to the glossary below for explanation of the terms used in the coordinate transformation.

\section{Coordinate transformation}

The coordinate transformations were done on data given in Cartesian coordinates. The first transformation is a rotation about the $z$-axis, so that the start point, $p$, lies on the $x, z$ plane (Fig. A1). First $\theta_{1}$ and $\theta_{2}$ are determined:

$$
\theta_{1}=\arctan \frac{\boldsymbol{x}_{\text {start }}}{y_{\text {start }}}
$$

and

$$
\begin{gathered}
\theta_{2}=\arctan \frac{z_{\text {start }}}{\sqrt{x_{\text {start }}^{2}+y_{\text {start }}^{2}}} \\
{\left[\begin{array}{l}
x \\
y \\
z
\end{array}\right]^{I}=\left[\begin{array}{ccc}
\cos \theta_{1} & \sin \theta_{1} & 0 \\
-\sin \theta_{1} & \cos \theta_{1} & 0 \\
0 & 0 & 1
\end{array}\right]\left[\begin{array}{l}
x \\
y \\
z
\end{array}\right]}
\end{gathered}
$$

In the second transformation, data were rotated around the $y^{I}$ axis aligning the start point $\left(x_{\text {start }}^{I}, y_{\text {start }}^{I}, z_{\text {start }}^{I}\right)$ on the $x^{I I}$ axis (Fig. A1).

$$
\left[\begin{array}{l}
x \\
y \\
z
\end{array}\right]^{I I}=\left[\begin{array}{ccc}
\cos \theta_{2} & 0 & \sin \theta_{2} \\
0 & 1 & 0 \\
-\sin \theta_{2} & 0 & \cos \theta_{2}
\end{array}\right]\left[\begin{array}{l}
x \\
y \\
z
\end{array}\right]^{I}
$$

In effect, the first 2 transformations align the $x^{I I}$ axis with a stream line. Finally, coordinates are rotated around the $x^{I I}$ axis aligning the end point on the $x^{I I}, y^{I I}$ plane as $x_{\text {end, }}^{I I} y_{\text {end }}^{I I}$ (Fig. A2). The rotation angle $\theta_{3}$ is determined by

$$
\theta_{3}=\arctan \frac{z_{\text {end }}^{I I}}{Y_{\text {end }}^{I I}}
$$

and the coordinate transformation is given by

$$
\left[\begin{array}{l}
x \\
y \\
z
\end{array}\right]^{I I I}=\left[\begin{array}{ccc}
1 & 0 & 0 \\
0 & \cos \theta_{3} & \sin \theta_{3} \\
0 & -\sin \theta_{3} & \cos \theta_{3}
\end{array}\right]\left[\begin{array}{l}
x \\
y \\
z
\end{array}\right]^{I I}
$$

\section{Correction for ambient water motions}

Since the siphon flow creates a radially symmetrical flow field around the siphon, the following approach can be used. The transformed Cartesian coordinates are converted into polar data coordinates, which are given in terms of radial distance and angle with respect to the siphon mouth. The siphon flow field, $u(r)$ is given by:

$$
u(r)=\frac{\mathrm{d} r}{\mathrm{~d} t}=-B r^{-2}
$$

where $B$ is an experimentally determined constant $(Q / 4 \pi)$, and $r$ is the radial position of a non-motile particle that follows the flow lines of the suction flow. Integrating with respect to $r$ yields:

$$
r_{(\Delta t)}=\left\{{r_{t_{0}}}^{3}-3 B \Delta t\right\}^{\frac{1}{3}}
$$

where $r_{t 0}$ is the initial position of the particle and $r_{(\Delta t)}$ is the radial position reached after time $\Delta t$. Thus, in a suction flow, the flow-corrected radial end-distance $\left(r^{*}\right)$ of a jumping organism can be calculated as:

$$
r_{e}^{*}=\left\{r_{e}^{3}+3 B \Delta t\right\}^{\frac{1}{3}}
$$

The tangential velocity of the organism is unaffected by the radial flow, so that $l=l^{*}$ (see Fig. A3). That is:

$$
\begin{aligned}
& r_{e}^{*}\left(\theta_{e}^{*}-\theta_{s}\right)=r_{e}\left(\theta_{e}-\theta_{s}\right) \\
& \mathbb{\Downarrow} \\
& \theta_{e}^{*}=\theta_{s}+\frac{r_{e}}{r_{e}^{*}}\left(\theta_{e}-\theta_{s}\right)
\end{aligned}
$$

The uncorrected apparent initial and end positions are calculated from the 2 nd transformed positions.

$$
\begin{gathered}
r_{S}=\sqrt{\left(x_{\text {start }}^{I I I}\right)^{2}+\left(y_{\text {start }}^{I I I}\right)^{2}} \\
r_{e}=\sqrt{\left(x_{\text {end }}^{I I I}\right)^{2}+\left(y_{\text {end }}^{I I I}\right)^{2}} \\
\theta_{s}=\arctan \frac{y_{\text {start }}^{I I I}}{x_{\text {start }}^{I I I}} \\
\theta_{e}=\arctan \frac{y_{\text {end }}^{I I I}}{x_{\text {end }}^{I I I}}
\end{gathered}
$$

Thus, the flow-corrected end position given by Cartesian coordinates is:

$$
\begin{aligned}
& y_{\text {end }}^{* I I I}=r_{e}^{*} \sin \theta_{e}^{*} \\
& x_{\text {end }}^{* \text { III }}=r_{e}^{*} \cos \theta_{e}^{*}
\end{aligned}
$$

The jump angle relative to flow line is given as

$$
\theta_{\alpha}^{*}=\arctan \frac{y_{\text {end }}^{* I I I}}{x_{\text {end }}^{* I I I}-x_{\text {start }}^{* I I I}}
$$

and the jump angle relative to gravity in back-transformed coordinates is given by:

$$
\theta^{*}=\arctan \frac{z_{\text {end }}^{*}-z_{\text {start }}}{\sqrt{\left(x_{\text {end }}^{*}-x_{\text {start }}\right)^{2}+\left(y_{\text {end }}^{*}-y_{\text {start }}\right)^{2}}}
$$

Finally, the angle of the flow line can be calculated as

$$
\theta_{\chi}=\arctan \frac{z_{\text {start }}}{\sqrt{x_{\text {start }}^{2}+y_{\text {start }}^{2}}}
$$




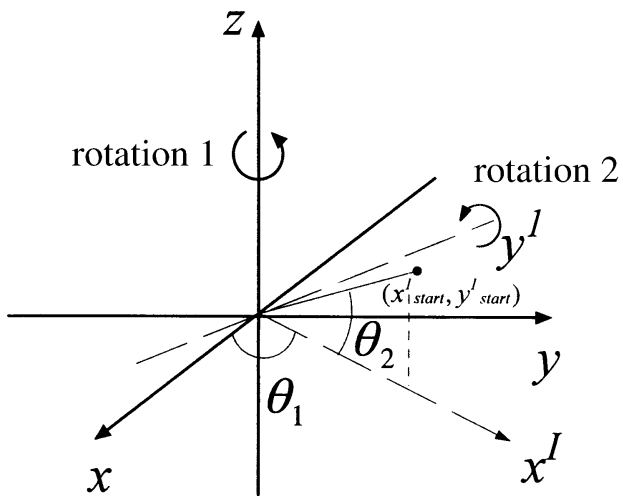

Fig. A1. First rotation of coordinate transformation, aligns the start point on the $x, z$ plane. In the second rotation data was rotated around the $y^{I}$ aligning the onset point $\left(x_{\text {start }}^{I}, y_{\text {start }}^{I}, z_{\text {start }}^{I}\right)$ on the $x^{I I}$ axis

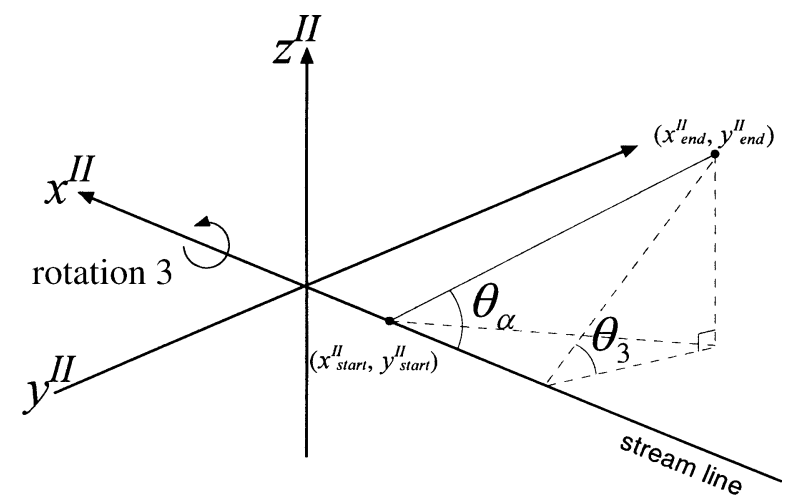

Fig. A2. In the third rotation data was rotated around the $x^{I I}$ axis aligning the end point on the $x^{I I I}, y^{I I I}$ plane as $x_{\text {end }}^{I I I}, z_{\text {end }}^{I I I}$
Fig. A3. Graphical representation of fluid motion correction in polar coordinates

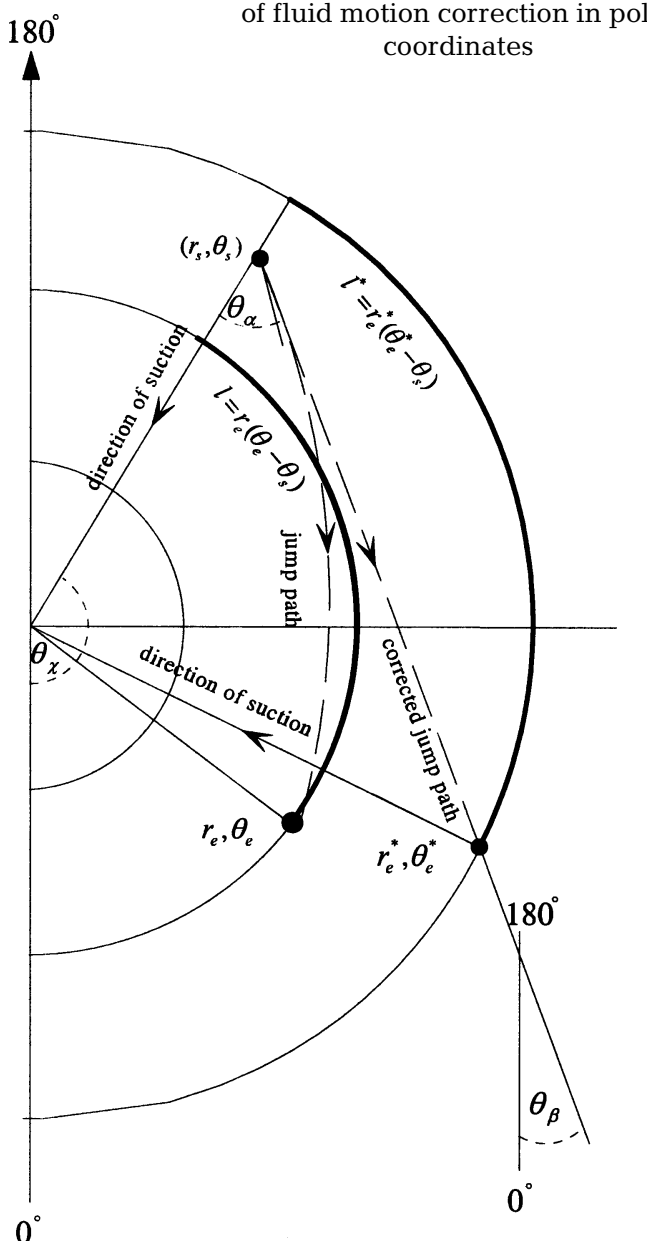

\section{Glossary}

\begin{tabular}{|c|c|c|}
\hline Term & Unit & Description \\
\hline$x_{\text {end }}^{I I I}$ & $\mathrm{~cm}$ & $x$ coordinate of transformed end position of jump \\
\hline$y_{\text {end }}^{I I I}$ & $\mathrm{~cm}$ & $y$ coordinate of transformed end position of jump \\
\hline$X_{\text {end }}^{* I I I}$ & $\mathrm{~cm}$ & $\begin{array}{l}x \text { coordinate of transformed end position of jump corrected for ambient water motions in the } \\
\text { jump trajectory plane }\end{array}$ \\
\hline$y_{\text {end }}^{* I I I}$ & $\mathrm{~cm}$ & $\begin{array}{l}y \text { coordinate of transformed end position of jump corrected for ambient water motions in the } \\
\text { jump trajectory plane }\end{array}$ \\
\hline$\theta_{s}$ & degree $\left(0-180^{\circ}\right)$ & Angular component of polar coordinates of start position \\
\hline$\theta_{e}$ & degree $\left(0-180^{\circ}\right)$ & Angular component of polar coordinates of end position before jump was corrected for flow \\
\hline$\theta_{e}^{*}$ & degree $\left(0-180^{\circ}\right)$ & Angular component of polar coordinates of end position after jump was corrected for flow \\
\hline$r_{e}$ & $\mathrm{~cm}$ & Radial component of polar coordinates of end position before jump was corrected for flow \\
\hline$r_{e}^{*}$ & $\mathrm{~cm}$ & Radial component of polar coordinates of end position after jump was corrected for flow \\
\hline \multirow[t]{3}{*}{$r_{S}$} & $\mathrm{~cm}$ & Radial component of polar coordinates of start position \\
\hline & degree $\left(0-180^{\circ}\right)$ & Jump angle relative to flow line corrected for ambient flow \\
\hline & degree $\left(0-180^{\circ}\right)$ & Jump angle relative to gravity corrected for ambient flow \\
\hline$\Delta t$ & $\mathrm{~S}$ & Jump duration \\
\hline$\Delta$ & $\mathrm{s}^{-1}$ & Deformation rate \\
\hline
\end{tabular}




\section{LITERATURE CITED}

Berg HC (1983) Random walks in biology. Princeton University Press, New Jersey

Burns CW, Gilbert JJ (1993) Predation on ciliates by freshwater calanoid copepods: rates of predation and relative vulnerabilities of prey. Freshw Biol 30:377-393

Buskey EJ, Hyatt C (1995) Effects of the Texas (USA) 'brown tide' alga on planktonic grazers. Mar Ecol Prog Ser 126: 285-292

Fields DM, Yen J (1996) The escape behaviour of Pleuromamma xiphias in response to a quantifiable fluid mechanical disturbance. In: Lenz PH, Hartline DK, Purcell JE, Macmillan DL (eds) Zooplankton: sensory ecology and physiology, Vol 1. Gordon \& Breach, Amsterdam, p 323-339

Frost BW (1972) Effects of size and concentration of food particles on the feeding behaviour of the marine planktonic copepod Calanus pacificus. Limnol Oceanogr 17:805-815

Gilbert JJ (1994) Jumping behaviour in the oligotrich ciliates Strobilidium velox and Halteria grandinella, and its significance as defence against rotifer predators. Microb Ecol 27:189-200

Gilbert JJ, Jack JD (1993) Rotifers as predators on small ciliates. Hydrobiologia 255/256:247-253

Häder D, Rosum A, Schaefer J, Hemmersbach R (1996) Graviperception in the flagellate Euglena gracilis during a shuttle space flight. J Biotechnol 47:261-269

Hansen G, Larsen J (1992) Dinoflagellater i danske farvande. In: Thomsen A (ed) Plankton i de indre danske farvande. Havforsk Miljøstyrrelsen 11:45-155 (in Danish)

Hansen PJ (1989) The red tide dinoflagellate Alexndrium tamarense: effect on behaviour and growth of a tintinnid ciliate. Mar Ecol Prog Ser 53:105-116

Hemmersbach R, Voormanns R, Briegleb W, Rieder N, Häder D (1996) Influence of accelerations on the spatial orientation of Loxodes and Paramecium. J Biotechnol 47:271-278

Jakobsen HH, Hansen PJ (1997) Prey size selection, grazing and growth response of the small heterotrophic dinoflagellate Gymnodinium sp. and the ciliate Balanion comatum - a comparative study. Mar Ecol Prog Ser 158: $75-86$

Jakobsen HH, Montagnes DJS (1999) A redescription of Balanion comatum Wulff, 1919 (Prorodotida, Ciliophora), with notes on its cultivation and behaviour. J Eukaryot Microbiol 46:198-205

Jonsson PR, Tiselius P (1990) Feeding behaviour, prey detection and capture efficiency of copepod Acartia tonsa feeding on planktonic ciliates. Mar Ecol Prog Ser 60:35-44

Kerfoot WC (1978) Combat between predatory copepods and their prey: cyclops, Epischoura and Bosminia. Limnol Oceanogr 23:1089-1102

Kiørboe T, Saiz E (1995) Planktivorous feeding in calm and turbulent environments, with emphasis on copepods. Mar Ecol Prog Ser 122:135-145

Kiørboe T, Visser AW (1999) Predation and prey preception in copepods due to hydrochemecanical signals. Mar Ecol Prog Ser 179:81-95

Kiørboe T, Saiz E, Viitasalo M (1996) Prey switching behaviour in the planktonic copepod Acartia tonsa. Mar Ecol Prog Ser 143:65-75

Kiørboe T, Saiz E, Visser AW (1999) Hydrodynamic signal perception in the copepod Acartia tonsa. Mar Ecol Prog Ser 179:97-111

Lavrentyev P (1995) Workbook on protist ecology and taxonomy. In: Setälä O, Kuuppo P, Ekbom J, Kuosa H, Patterson DJ (eds) Proceedings of the First Workshop on Protistology at Tvärminne Zoological Station 1992. Ylipistopanino, Helsinki, p 131-138

Machemer H, Bräucker R (1992) Gravireception and graviresponses in ciliates. Acta Protozool 31:185-214

Montagnes DJS, Lynn DH (1991) Taxonomy of choreotrichs, the major marine planktonic ciliates, with emphasis on the aloricate forms. Mar Microb Food Webs 5:59-74

Naitoh Y, Eckert R (1969) Ionic mechanisms controlling behavioral responses of Paramecium to mechanical stimulation. Science 164:963-965

Nielsen TG, Kiørboe T (1994) Regulation of zooplankton biomass and production in a temperate coastal ecosystem. 2 . ciliates. Limnol Oceanogr 39:508-519

Sokal RR, Rohlf FJ (1998) Biometry: the principles and practice of statistics in biological research. WH Freeman and Company, New York

Stoecker DK, Capuzzo JM (1990) Predation on protozoa: its importance to zooplankton. J Plankton Res 12:891-908

Støttrup J, Richardson K, Kirkegaard E, Pihl NJ (1986) The cultivation of Acartia tonsa Dana for use as a live food source for marine fish lavae. Aquaculture 52:87-96

Strickler JR (1985) Feeding currents of calanoid copepods: two new hypotheses. In: Laverack MS (ed) Physiological adaptations in marine animals. Society for Experimental Biology, London, p 459-485

Strickler JR, Bal AK (1973) Setae of the first antenna of the copepod Cyclops sutifer (Sars): their structure and importance. Proc Natl Acad Sci USA 70:2656-2659

Svensen C, Kiørboe T (2000) Remote prey detection in Oithona similis: hydromechanical vs. chemical cues. J Plankton Res 22:1155-1166

Tamar H (1965) The culture, structure, and locomotion of Halteria grandinella. Acta Protozool 3:165-172

Tamar H (1979) The movement of jumping ciliates. Arch Protistenkd 122:290-327

Tamar H (1992) Four marine species of Mesodinium (Ciliophora: Mesodiniidae). II. Mesodinium pulex Claph. \& Lachm. 1858. Arch Protistenkd 141:284-303

Tiselius P, Jonsson PR (1990) Foraging behaviour of six calanoid copepods: observations and hydrodynamic analysis. Mar Ecol Prog Ser 66:23-33

van Duren LA, Videler JJ (1995) Swimming behaviour of developmental stages of the calanoid copepod Temora longicornis at different food concentrations. Mar Ecol Prog Ser 126:153-161

Visser AW, Jonsson PR (2000) On the reorientation of nonspherical prey particles in a feeding current. J Plankton Res 22:761-777

Wiackowski K, Brett MT, Goldman CR (1994) Differential effects of zooplankton species on ciliate community structure. Limnol Oceanogr 39:486-492

Wickham SA (1995) Cyclops predation on ciliates: speciesspecific differences and functional responses. J Plankton Res 17:1633-1646

Yen J, Fields DM (1992) Escape response of Acartia hudsonica (Copepoda) naupli from the flow field of Temora longicornis (Copepoda). Ergeb Limnol 36:123-134

Submitted: February 18, 2000; Accepted: August 22, 2000

Proofs received from author(s): March 30, 2001 